\title{
Beneficial Effect of a Novel Diuretic, M17055, on Blood Pressure and Cardiovascular Hypertrophy in Spontaneously Hypertensive Rats
}

\author{
Tomoaki Shinkawa, Yutaka Kato, Naoko Tsuchiya, Fumiaki Yamasaki, Akio Uemura and Masahiro Mizota
}

Fuji Central Research Laboratory, Mochida Pharmaceutical Co., Ltd., 722 Jinba-aza-Uenohara, Gotemba, Shizuoka 412, Japan

Received April 5, $1993 \quad$ Accepted July 19, 1993

\begin{abstract}
We investigated the effects of a novel diuretic, M17055, on blood pressure and cardiovascular hypertrophy in spontaneously hypertensive rats (SHR). M17055 was orally administered once a day for 24 consecutive days to 14-week-old male SHR. M17055 at doses of $1.25,2.5$ and $5 \mathrm{mg} / \mathrm{kg} /$ day exerted a doserelated diuretic and antihypertensive effect during the treatment. The weight of the left ventricle normalized by body weight on the following day of the last dosage was significantly $(\mathrm{P}<0.01)$ reduced by M17055 at doses of 2.5 and $5 \mathrm{mg} / \mathrm{kg} /$ day in a dose-dependent manner. The effect of M17055 on cardiac hypertrophy was more potent $(\mathrm{P}<0.01)$ than that of captopril, when the comparison was performed at the doses of M17055 and captopril inducing the same extent of blood-pressure decrement. Vascular hypertrophy was evaluated by the media/lumen ratio $(\mathrm{M} / \mathrm{L})$ in the thoracic aorta and the first branch of the superior mesenteric artery. In the aorta, $\mathrm{M} / \mathrm{L}$ was slightly, but not significantly, decreased by $\mathrm{M} 17055$ at doses of 2.5 and $5 \mathrm{mg} / \mathrm{kg} /$ day, whereas it was decreased significantly $(\mathrm{P}<0.01)$ by captopril. In the mesenteric artery, the ratio was significantly $(\mathrm{P}<0.05)$ reduced by $\mathrm{M} 17055$ at a dose of $5 \mathrm{mg} / \mathrm{kg} / \mathrm{day}$. These results suggest that M17055 possesses beneficial properties for the clinical treatment of hypertension.
\end{abstract}

Keywords: M17055, Loop diuretic, Antihypertensive therapy, Cardiovascular hypertrophy, Spontaneously hypertensive rats (SHR)

Diuretics, mainly thiazide diuretics, are used in antihypertensive therapy as one of the first-choice drugs (1). Occasionally, the adverse effects of thiazide diuretics on sugar, lipids or uric acid metabolism limit their therapeutic use for long-term treatment $(2,3)$. However, the treatment of hypertension with diuretics is still effective and important, especially in a population with high $\mathrm{NaCl}$ intake like the Japanese.

It is recognized that the improvement of cardiovascular hypertrophy is also an important clinical target for the treatment of hypertension besides reducing blood pressure (4-6). Among the available antihypertensive agents, ACE inhibitors appear to be the most potent ones for preventing left ventricular hypertrophy (7). In contrast, it has been demonstrated that thiazide diuretics exhibit little effect on cardiac hypertrophy (7-9), and there are yet no reports on their effect on vascular hypertrophy. In the case of loop diuretics, there have been no reports on the possible prevention of cardiovascular hypertrophy.

M17055 [7-chloro-2,3-dihydro-1-(2-methylbenzoyl)$4(I H)$-quinolinone 4-oxime- $O$-sulfonic acid potassium salt] is a "high ceiling" diuretic that belongs to a novel family of diuretics, the quinolinone oxime sulfonic acids (10). As shown in Fig. 1, the chemical structure of M17055 is quite different from known diuretics belonging to the loop or the thiazide diuretics. Our previous study has revealed that this novel diuretic acts not only on the thick ascending limb of Henle's loop via the inhibition of $\mathrm{Na}^{+}, \mathrm{K}^{+}, 2 \mathrm{Cl}^{-}$-cotransport but also acts on the distal nephron segments via the inhibition of $\mathrm{Na}^{+}$transport like<smiles>Cc1ccccc1C(=O)N1CCC(=NS(=O)(=O)O[Na])c2ccc(Cl)cc21</smiles>

Fig. 1. Chemical structure of M17055. 
amiloride (11). This unique mechanism of action of M17055 is reflected in its effect on the proportion of urinary electrolyte excretion, i.e., M17055 shows less kaliuretic and calciuric effects than furosemide at a comparable level of natriuresis in dogs, rats and mice $(11,12)$. These characteristics of M17055 seem preferable for the longterm treatment of hypertension. It is therefore important to evaluate the possible therapeutic value of such a drug for the treatment of either hypertension or cardiovascular hypertrophy.

In the present study, we examined comparatively the effects of a 24-day treatment with M17055 and captopril, an ACE inhibitor, on blood pressure and cardiovascular hypertrophy in spontaneously hypertensive rats (SHR), a common animal model for human essential hypertension.

\section{MATERIALS AND METHODS}

\section{Animals}

Male SHR and Wistar Kyoto rats (WKY) at 11-weekold were purchased from Charles River Japan (Atsugi). They were kept in an air-conditioned room with a temperature of $23 \pm 2^{\circ} \mathrm{C}$ and humidity of $55 \pm 10 \%$ on a 12 -hr light-dark cycle, and fed a normal diet (CE-2; Clea Japan, Tokyo) with water provided ad libitum. Each animal was housed in an individual metabolic cage since the age of 12 weeks.

\section{Drugs}

M17055 was synthesized and supplied by Hodogaya Chemical Co., Ltd. (Tokyo). Captopril was purchased from Sigma Chemical Co. (St. Louis, MO, USA). Sodium pentobarbital (Somunopentil ${ }^{\mathbb{B}}$ ) was obtained from Pitman Moore, Inc. (Washington Crossing, NJ, USA). All other agents used in this study were of reagent grade.

\section{Experimental protocol}

Drugs were administered orally by gavage with $5 \mathrm{ml} / \mathrm{kg}$ of distilled water containing $5 \%$ gum arabic for 24 consecutive days in SHR since the age of 14 weeks. Blood pressure and urine volume measurements were started one week before the initiation of the drug administration and continued throughout the administration period every 2 or 3 days. Blood pressure was measured by the tail cuff method with a sphygmomanometer, PS-600 (Riken Kaihatsu, Machida), in the morning before the drug administration. To evaluate the antihypertensive effects of the drugs, we calculated the average of all the data of blood pressure measured during the administration period in each animal. Urinary concentrations of $\mathrm{Na}^{+}$ and $\mathrm{K}^{+}$were assayed by flame photometry, and $\mathrm{Cl}^{-}$was measured by coulometry (Autoanalyzer for electrolytes, Model 710; Hitachi, Tokyo).
On the following day of the last drug administration, the blood, heart and blood vessels were obtained from the animal.

\section{Blood sampling and measurements}

Animals were anesthetized with a dose of $40 \mathrm{mg} / \mathrm{kg}$, i.p. of sodium pentobarbital. After a laparotomy along the median line, arterial blood was collected through the abdominal aorta with a heparinized syringe. Plasma was separated by centrifugation. Plasma concentrations of $\mathrm{Na}^{+}$, $\mathrm{K}^{+}$and $\mathrm{Cl}^{-}$were determined by the method used for determination of the urinary concentrations (Autoanalyzer for electrolytes, Model 710; Hitachi). Plasma concentrations of $\mathrm{Ca}^{2+}$ and $\mathrm{Mg}^{2+}$ were determined by atomic absorption (Z-8100, Hitachi). Plasma concentrations of triglyceride, total cholesterol, urea nitrogen and creatinine were assayed by the respective enzymatic methods using triglyceride E-test ${ }^{(\mathbb{R})}$ Wako, cholesterol E-test ${ }^{\mathbb{R}}$ Wako, urea nitrogen B-test ${ }^{\mathrm{B}}$ Wako (Wako Pure Chemical Industries, Co., Osaka) and detaminar ${ }^{\mathscr{Q}}$ CRE555 (Kyowa Medex, Co., Ltd., Tokyo), respectively. Plasma renin activity and aldosterone concentration were determined by radioimmunoassay using Renin-Riabead ${ }^{\mathbb{B})}$ (Dainabot, Co., Ltd., Tokyo) and SPAC-S aldosterone kit (Daiichi Radioisotope Labs., Ltd., Tokyo), respectively.

\section{Measurement of the left ventricular weight}

Following the blood sampling, the heart was removed and put into ice-cold, $0.9 \% \mathrm{NaCl}$ solution containing 100 $\mathrm{U} / \mathrm{ml}$ of heparin to rest in the diastolic state. The atrium and the right ventricular wall were removed. The left ventricle was cut into a sheet, and then its wet weight was measured after sufficient blotting on filter paper.

\section{Measurement of the structure of aorta}

The procedures were conducted according to the method described by Richer et al. (13) with a minor modification as follows: briefly, the thoracic aorta was removed between the end of the arch and the diaphragm. After removing the surrounding connective tissues, the aorta was fixed in a $10 \%$ formaldehyde-phosphate buffer solution $(\mathrm{pH}=7.2)$. The tissue was embedded in paraffin wax, cut into a $5-\mu \mathrm{m}$-thick cross-section in a usual way at about the middle of the specimen, and stained by Azan's method. The medial and luminal areas were measured by an image analyzer (Luzex 5000X; Nireco, Tokyo), and then the media/lumen ratio $(\mathrm{M} / \mathrm{L})$ was calculated.

\section{Measurement of the structure of mesenteric arteries}

The procedures were performed according to the method described by Lee et al. (14) with a slight modification as follows: after blood sampling, a small incision was 
made on the abdominal aorta in order to insert a catheter for infusion. Through the catheter placed in the superior mesenteric artery, an infusion of $37^{\circ} \mathrm{C}$ Krebs solution (composition: $118 \mathrm{mM} \mathrm{NaCl}, 25 \mathrm{mM} \mathrm{NaHCO}, 4.7 \mathrm{mM}$ $\mathrm{KCl}, 1.2 \mathrm{mM} \mathrm{KH}_{2} \mathrm{PO}_{4}, 1.17 \mathrm{mM} \mathrm{MgSO}_{4} \cdot 7 \mathrm{H}_{2} \mathrm{O}, 2.5 \mathrm{mM}$ $\mathrm{CaCl}_{2}$ and $5.6 \mathrm{mM}$ glucose, adjusted to $\mathrm{pH} 7.3$ by bubbling with $95 \%$ oxygen and $5 \%$ carbon dioxide) was started at a flow rate of $210 \mathrm{ml} / \mathrm{hr}$. The portal vein was cut for the drainage of the perfusate. To obtain the maximum dilation of the vessels, a 15-min infusion with the Krebs solution was performed and followed by a further 5 -min infusion with $10 \%$ formaldehyde-phosphate buffer solution for tissue fixation. The mesenteric vascular bed supplying a part of the proximal jejunum was removed and put into the fixation solution. Four or five specimens of the first branch of the superior mesenteric artery with a lumen diameter range of $140-270 \mu \mathrm{m}$ were taken from each animal. The following procedure to prepare the cross-sections of mesenteric arteries was similar to that for the aorta as described above. The $M / L$ value for each animal was calculated as an average of 4 or 5 specimens. These assessment procedures were applied to groups (6 animals in each) of WKY, control SHR and SHR treated with 5 $\mathrm{mg} / \mathrm{kg} / \mathrm{day}$ of M17055.

\section{Statistical analyses}

All values are expressed as the means \pm S.E.M. Statistical analysis was performed with Bonferroni's multiple comparison test following the one-way analysis of variance (ANOVA). A $P$ value less than 0.05 was considered statistically significant.

\section{RESULTS}

\section{Antihypertensive effect}

M17055 at doses of $1.25,2.5$ and $5 \mathrm{mg} / \mathrm{kg} /$ day tended to reduce blood pressure in a dose-related manner during the administration period in SHR (Fig. 2). The mean ( \pm S.E.M.) averaged blood pressure during the administration period is shown in Fig. 3. The averaged $m m \mathrm{Hg}$ blood pressure values in the control group of SHR and M17055-treated groups at doses of $1.25,2.5$ and 5 $\mathrm{mg} / \mathrm{kg} /$ day were $183 \pm 2$ and $182 \pm 2,179 \pm 3$ and $167 \pm 2$ ( $\mathrm{P}<0.01$ vs. control SHR), respectively. Captopril at a dose of $30 \mathrm{mg} / \mathrm{kg} /$ day also showed a sustained antihypertensive effect during the administration period with the mean averaged blood pressure of $170 \pm 1 \mathrm{mmHg}(\mathrm{P}<0.01$ vs. control SHR, Fig. 3).

\section{Diuretic effect}

Figure 4 shows the changes in urine volume and urinary excretions of $\mathrm{Na}^{+}, \mathrm{Cl}^{-}$and $\mathrm{K}^{+}$in $24 \mathrm{hr}$ during the experiment. The urine volume and urinary excretions of $\mathrm{Na}^{+}$

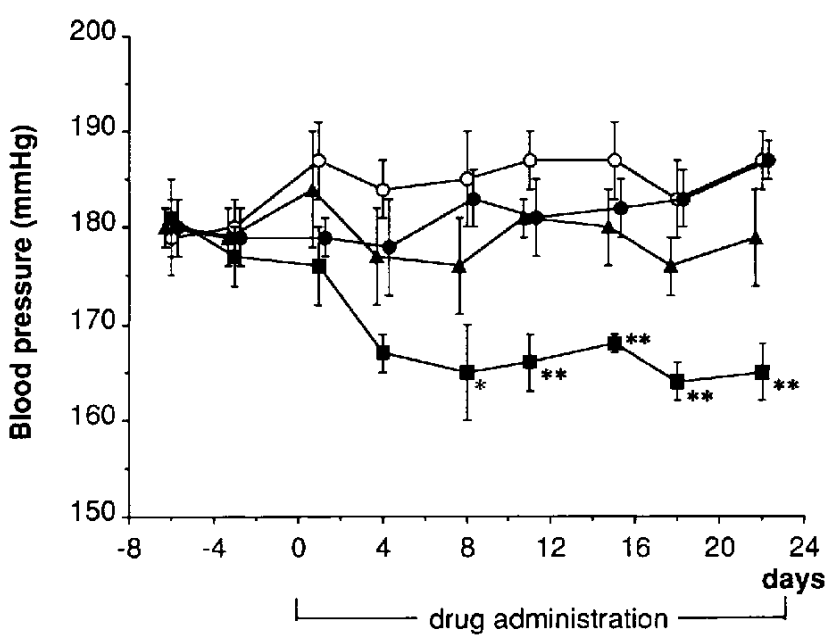

Fig. 2. Blood pressure effect of oral administration of M17055 for 24 days at $1.25(\mathbf{O}), 2.5(\mathbf{A})$ and $5(\square) \mathrm{mg} / \mathrm{kg} / \mathrm{day}$ in SHR. Control animals $(O)$ were given the vehicle at $5 \mathrm{ml} / \mathrm{kg} /$ day. Blood pressure was measured in the morning before the drug administration by the tail cuff method. All values are expressed as the mean \pm S.E.M. of six animals. ${ }^{*}: \mathrm{P}<0.05,{ }^{* *}: \mathrm{P}<0.01$, as compared with the value of the control group in SHR by Bonferroni's multiple comparison.

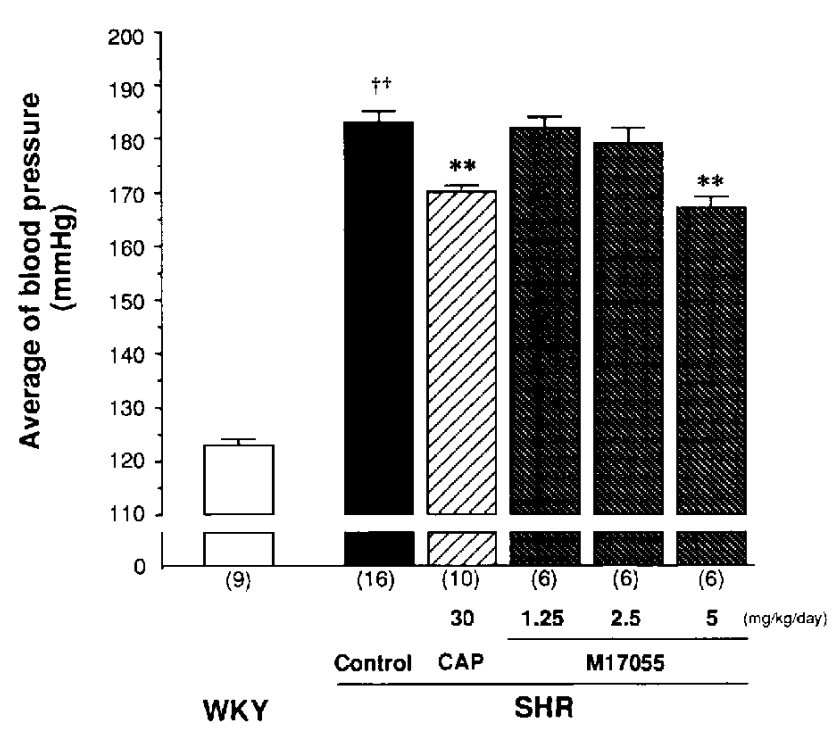

Fig. 3. Average value of blood pressure during the 24-day treatment with M17055 or captopril (CAP) in SHR. All values are expressed as mean \pm S.E.M. Numbers in parentheses show the numbers of animals in each group. ${ }^{\dagger}: \mathrm{P}<0.01$, as compared with the value of WKY; ${ }^{* *}: \mathrm{P}<0.01$, as compared with the value of the control group in SHR by Bonferroni's multiple comparison.

and $\mathrm{Cl}^{-}$tended to increase in the groups treated with M17055 at doses of 1.25 and $2.5 \mathrm{mg} / \mathrm{kg} / \mathrm{day}$ to a similar extent, and they increased further in the group given the dose of $5 \mathrm{mg} / \mathrm{kg} / \mathrm{day}$. Urinary excretion of $\mathrm{K}^{+}$was comparable among the control and M17055-treated groups. 

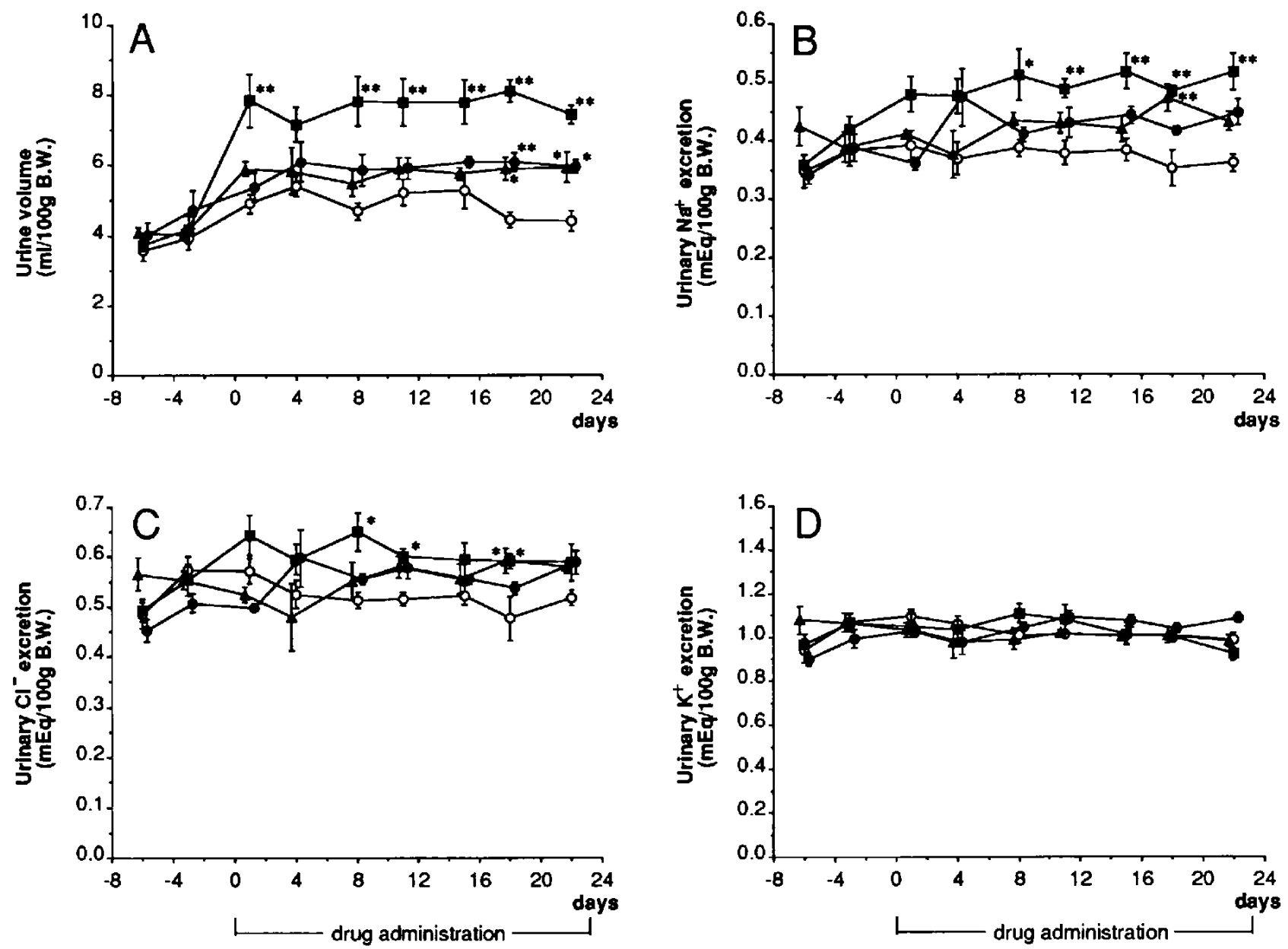

Fig. 4. Effect of M17055 on urine volume (A), urinary $\mathrm{Na}^{+}$(B), $\mathrm{Cl}^{-}$(C) and $\mathrm{K}^{+}$(D) excretion in 24 hr during its oral administration for 24 days at $1.25(O), 2.5(\Delta)$ and $5(\square) \mathrm{mg} / \mathrm{kg} /$ day in SHR. Control animals $(O)$ were given the vehicle at 5 $\mathrm{ml} / \mathrm{kg} /$ day. All values are expressed as the mean \pm S.E.M. of six animals. ${ }^{*}: \mathrm{P}<0.05,{ }^{* *}: \mathrm{P}<0.01$, as compared with the value of the control group in SHR by Bonferroni's multiple comparison.

\section{Effect on the left ventricular weight}

The mean body weight and left ventricular weight on the following day of the last dosage of the drug are summarized in Table 1. No significant change was observed in the body weight among the groups. In the control SHR, the left ventricular weight was significantly $(\mathrm{P}<0.01)$ greater than that in WKY. The values were significantly $(\mathrm{P}<0.01)$ reduced in the groups treated with captopril and M17055 at a dose of $5 \mathrm{mg} / \mathrm{kg} /$ day as compared with control SHR.

The mean left ventricular weight normalized by body weight (LV/BW) is shown in Fig. 5. The LV/BW in SHR was significantly $(\mathrm{P}<0.01)$ higher than that in WKY. After the treatment with M17055 at doses of 2.5 and 5 $\mathrm{mg} / \mathrm{kg} / \mathrm{day}$, the $\mathrm{LV} / \mathrm{BW}$ was significantly $(\mathrm{P}<0.01)$ reduced in a dose-dependent manner. Although the treatment with captopril at a dose of $30 \mathrm{mg} / \mathrm{kg} /$ day also significantly $(\mathrm{P}<0.05)$ reduced the $\mathrm{LV} / \mathrm{BW}$ compared with the control group, the mean value was significantly $(\mathrm{P}<0.01)$ higher than that in the group treated with

Table 1. Body weight (BW) and left ventricular weight (LV) on the day following the last administration of M17055 or captopril in the treated SHR compared with those observed in the control SHR and untreated WKY

\begin{tabular}{llrrcc}
\hline Strain & Treatment & $\begin{array}{c}\text { Dose } \\
(\mathrm{mg} / \mathrm{kg} / \text { day) }\end{array}$ & $\mathrm{n}$ & $\begin{array}{c}\mathrm{BW} \\
(\mathrm{g})\end{array}$ & $\begin{array}{c}\mathrm{LV} \\
(\mathrm{g})\end{array}$ \\
\hline SHR & Control & & 16 & $335 \pm 5$ & $0.89 \pm 0.01^{++}$ \\
& Captopril & 30 & 10 & $319 \pm 5$ & $0.80 \pm 0.01^{* *}$ \\
& M17055 & 1.25 & 6 & $340 \pm 4$ & $0.87 \pm 0.01$ \\
& & 2.5 & 6 & $351 \pm 3$ & $0.87 \pm 0.02$ \\
& & 5 & 6 & $354 \pm 6$ & $0.80 \pm 0.02^{* *}$ \\
WKY & Untreated & & 9 & $340 \pm 4$ & $0.75 \pm 0.02$ \\
\hline
\end{tabular}

All values are expressed as the mean \pm S.E.M. ${ }^{\#}: \mathrm{P}<0.01$ vs. WKY, ${ }^{* *}$ : $\mathbf{P}<0.01$ vs. control SHR by Bonferroni's multiple comparison. 


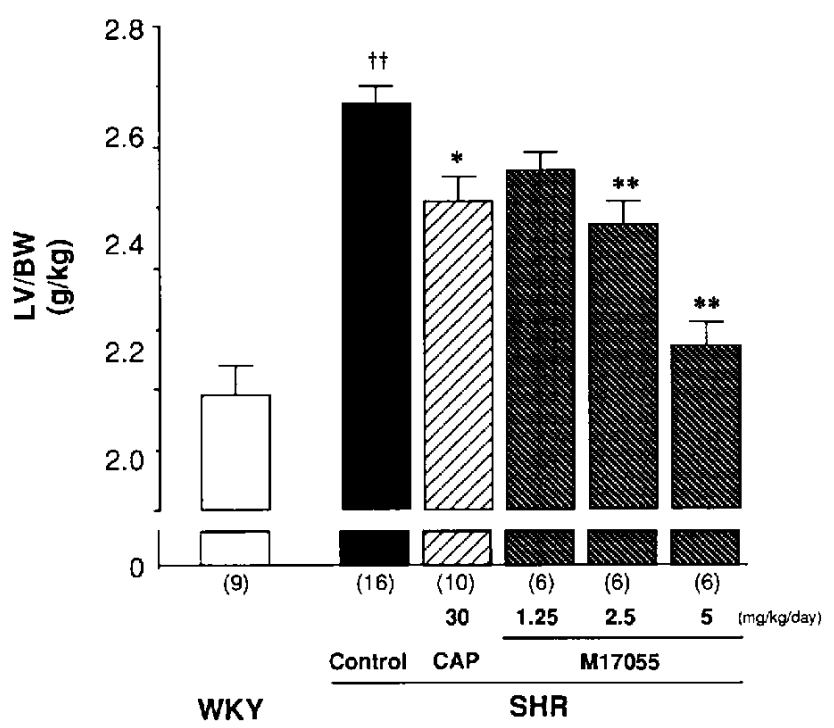

Fig. 5. Left ventricular weight normalized by body weight (LV/BW) after the 24-day treatment with M17055 or captopril (CAP) in SHR. Control SHR were given the vehicle at $5 \mathrm{ml} / \mathrm{kg} /$ day for 24 days. All values are expressed as the mean \pm S.E.M. Numbers in parentheses show the number of animals in each group. H. $\mathrm{P}<0.01$, as compared with the value of WKY; *: $\mathrm{P}<0.05$, **: $\mathbf{P}<0.01$, as compared with the value of the control SHR group by Bonferroni's multiple comparison.

M17055 at $5 \mathrm{mg} / \mathrm{kg} /$ day and was almost the same as that in the group treated with M17055 at a dose of 2.5 $\mathrm{mg} / \mathrm{kg} /$ day (Fig. 5).

\section{Effect on the vascular structures}

As shown in Fig. 6, the $\mathrm{M} / \mathrm{L}$ of the aorta was significantly greater in the control SHR than that in WKY. M17055 at doses of 2.5 and $5 \mathrm{mg} / \mathrm{kg} /$ day tended to lower the $\mathrm{M} / \mathrm{L}$. However, these changes were not statistically significant. Captopril at $30 \mathrm{mg} / \mathrm{kg} / \mathrm{day}$ significantly $(\mathrm{P}<0.01)$ reduced the $\mathrm{M} / \mathrm{L}$ of the aorta.

The $\mathrm{M} / \mathrm{L}$ ratios of the mesenteric arteries in WKY, the control SHR and SHR treated with M17055 at a dose of 5 $\mathrm{mg} / \mathrm{kg} /$ day are summarized in Fig. 7. The M/L was significantly $(P<0.01)$ greater in the control SHR than that in WKY. The treatment with M17055 significantly $(P<0.05)$ reduced the $M / L$ of the mesenteric arteries in SHR.

\section{Laboratory measurements}

Table 2 summarizes the plasma electrolyte concentrations on the following day of the last dosage of M17055 in the treated SHR and these data from the control SHR and untreated WKY. Significant $(P<0.01)$ differences in the plasma concentration of $\mathrm{Na}^{+}, \mathrm{Cl}^{-}, \mathrm{Ca}^{2+}$ and $\mathrm{Mg}^{2+}$ were observed between SHR and WKY. M17055 caused no significant change in the plasma electrolyte concentra-

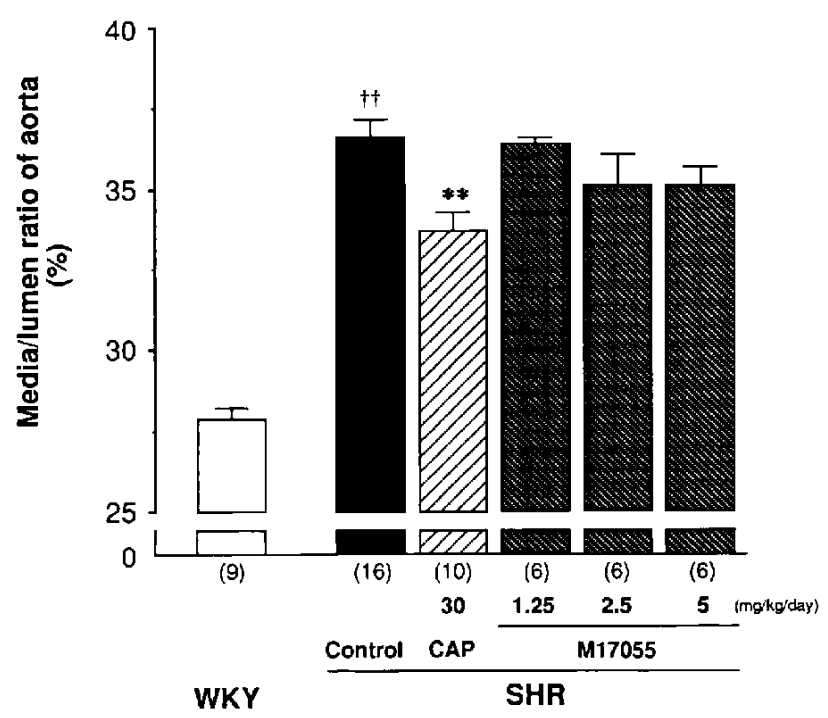

Fig. 6. Media/lumen ratio of thoracic aorta after the 24-day treatment of SHR with M17055 or captopril (CAP). Control SHR were given the vehicle at $5 \mathrm{ml} / \mathrm{kg} / \mathrm{day}$ for 24 days. All values are expressed as the mean \pm S.E.M. Numbers in parentheses show the number of animals in each group. ${ }^{+}: \mathrm{P}<0.01$, as compared with the value of WKY; ${ }^{* *}: \mathrm{P}<0.01$, as compared with the value of the control group in SHR by Bonferroni's multiple comparison.

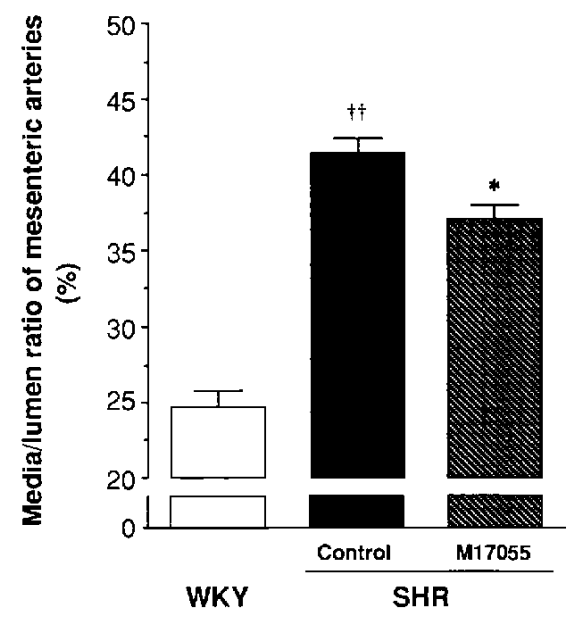

Fig. 7. Media/lumen ratio of mesenteric arteries after the 24-day treatment with M17055 at $5 \mathrm{mg} / \mathrm{kg} /$ day in SHR. Control SHR were given the vehicle at $5 \mathrm{ml} / \mathrm{kg} /$ day for 24 days. All values are expressed as the mean \pm S.E.M. of six animals. ${ }^{\ddagger}: \mathbf{P}<0.01$, as compared with the value of WKY; ${ }^{*}: \mathrm{P}<0.05$, as compared with the value of the control SHR by Bonferroni's multiple comparison.

tions as listed in Table 2.

Table 3 summarizes the plasma concentrations of triglyceride, total cholesterol, urea nitrogen and creatinine. M17055 exerted no significant influence on all the parameters as listed in Table 3. 
Table 2. Plasma electrolyte concentrations on the day following the last administration of M17055 in the treated SHR compared with those observed in the control SHR and untreated WKY

\begin{tabular}{llccccccc}
\hline Strain & Treatment & $\begin{array}{c}\text { Dose } \\
(\mathrm{mg} / \mathrm{kg} / \text { day })\end{array}$ & $\mathrm{n}$ & $\begin{array}{c}\mathrm{Na}^{+} \\
(\mathrm{mEq} / \mathrm{l})\end{array}$ & $\begin{array}{c}\mathrm{K}^{+} \\
(\mathrm{mEq} / \mathrm{l})\end{array}$ & $\begin{array}{c}\mathrm{Cl}^{-} \\
(\mathrm{mEq} / \mathrm{l})\end{array}$ & $\begin{array}{c}\mathrm{Ca}^{2+} \\
(\mathrm{mEq} / \mathrm{l})\end{array}$ & $\begin{array}{c}\mathrm{Mg}^{2+} \\
(\mathrm{mEq} / \mathrm{l})\end{array}$ \\
\hline SHR & Control & & 6 & $146.8 \pm 0.8^{\dagger+}$ & $4.57 \pm 0.12$ & $105.3 \pm 0.8^{++}$ & $4.92 \pm 0.05^{++}$ & $1.74 \pm 0.07^{H+}$ \\
& M17055 & 1.25 & 6 & $146.9 \pm 0.4$ & $4.59 \pm 0.11$ & $106.8 \pm 0.4$ & $4.86 \pm 0.02$ & $1.62 \pm 0.04$ \\
& & 2.5 & 6 & $147.9 \pm 0.5$ & $4.48 \pm 0.15$ & $106.1 \pm 0.5$ & $4.78 \pm 0.04$ & $1.68 \pm 0.02$ \\
\multirow{2}{*}{ WKY } & Untreated & 5 & 6 & $147.7 \pm 0.3$ & $4.27 \pm 0.12$ & $103.0 \pm 0.9$ & $4.89 \pm 0.03$ & $1.66 \pm 0.01$ \\
\hline
\end{tabular}

All values are expressed as the mean \pm S.E.M. ${ }^{\Uparrow t}: \mathrm{P}<0.01$ vs. WKY by Bonferroni's multiple comparison.

Table 3. Plasma concentrations of triglyceride, total cholesterol, urea nitrogen and creatinine on the day following the last administration of M17055 in the treated SHR compared with those observed in the control SHR and untreated WKY

\begin{tabular}{|c|c|c|c|c|c|c|c|}
\hline Strain & Treatment & $\begin{array}{c}\text { Dose } \\
\text { (mg/kg/day) }\end{array}$ & $\mathrm{n}$ & $\begin{array}{l}\text { Triglyceride } \\
\text { (mg/dl) }\end{array}$ & $\begin{array}{l}\text { Cholesterol } \\
\text { (mg/dl) }\end{array}$ & $\begin{array}{l}\text { Urea nitrogen } \\
\text { (mg/dl) }\end{array}$ & $\underset{\text { (mg/dl) }}{\text { Creatinine }}$ \\
\hline \multirow[t]{3}{*}{ SHR } & Control & & 6 & $83.5 \pm 8.7$ & $54.7 \pm 1.9^{\dagger \dagger}$ & $22.7 \pm 0.6$ & $0.38 \pm 0.02$ \\
\hline & & 2.5 & 6 & $75.9 \pm 7.2$ & $51.2 \pm 1.3$ & $23.1 \pm 0.5$ & $0.36 \pm 0.02$ \\
\hline & & 5 & 6 & $83.0 \pm 5.8$ & $51.5 \pm 0.5$ & $24.1 \pm 0.6$ & $0.38 \pm 0.01$ \\
\hline WKY & Untreated & & 9 & $102.2 \pm 7.9$ & $87.0 \pm 2.6$ & $20.4 \pm 0.7$ & $0.36 \pm \mathbf{0 . 0 1}$ \\
\hline
\end{tabular}

All values are expressed as the mean \pm S.E.M. ${ }^{\Uparrow t}: \mathrm{P}<0.01$ vs. WKY by Bonferroni's multiple comparison.

The plasma renin activity in the control group of SHR was $8.99 \pm 0.55 \mathrm{ng} / \mathrm{ml} / \mathrm{hr}$, which was similar to that observed in WKY $(8.58 \pm 0.88 \mathrm{ng} / \mathrm{ml} / \mathrm{hr})$. The treatment with captopril at a dose of $30 \mathrm{mg} / \mathrm{kg} /$ day and with M17055 at a dose of $5 \mathrm{mg} / \mathrm{kg} /$ day significantly elevated the plasma renin activity on the following day of the last dosage of the drug to $16.01 \pm 2.02(\mathrm{P}<0.01$ vs. control SHR) and $14.47 \pm 1.09(\mathrm{P}<0.05$ vs. control SHR), respectively. The plasma aldosterone concentrations in WKY, the control SHR, SHR treated with captopril at a dose of $30 \mathrm{mg} / \mathrm{kg} / \mathrm{day}$ and M17055 at a dose of $5 \mathrm{mg} / \mathrm{kg} /$ day were $52.9 \pm 12.6, \quad 199.9 \pm 35.1, \quad 118.5 \pm 25.4$ and $263.5 \pm 39.2 \mathrm{pg} / \mathrm{ml}$, respectively. The value in the control SHR was significantly $(\mathrm{P}<0.05)$ higher than that in WKY. Although no statistically significant difference among the 3 groups of SHR was observed, captopril showed a tendency to reduce the plasma aldosterone concentration; and in contrast, M17055 tended to elevate it as compared with the control SHR.

\section{DISCUSSION}

The aim of antihypertensive therapy is mainly to prevent various organ failures secondarily induced by chronic hypertension. Among such failures, cardiovascular hypertrophy is thought to be the most important one. Although cardiac hypertrophy is due to an adaptive mechanism against prolonged arterial hypertension, an advanced hypertrophy of the left ventricle induces some types of adverse cardiac status such as reduction in left ventricular compliance, impairment of coronary reserve, ventricular ectopy and impaired contractile function (7). Moreover, vascular hypertrophy causes peripheral organ damage and maintenance of elevated blood pressure (15). Among the first-choice drugs for antihypertensive therapy (1), ACE inhibitors, calcium- and $\beta$-blockers are able to improve cardiovascular hypertrophy (16-18). Concerning thiazide diuretics, it is generally recognized that they have little or no preventive effect on cardiac hypertrophy (7-9) and no reports have been made about their effect on vascular hypertrophy. These characteristics, together with the adverse effects on metabolic function, may be reflected in the results of several prospective trials that diuretic therapy effectively prevents stroke but not mortality from ischemic heart disease (19-22). Loop diuretics like furosemide are also included in the agents used in the antihypertensive therapy. However, the pharmacodynamic properties of furosemide, i.e., a fast onset and short duration of the high ceiling diuretic effect, restrict its usage as an antihypertensive drug. This could be the reason why there have been no discussions about the effect of loop diuretics on cardiovascular hypertrophy.

M17055 is a novel type of diuretic which acts not only on the thick ascending limb of Henle's loop but also acts 
on the distal nephron segments via the inhibition of $\mathrm{Na}^{+}$ transport like amiloride, a potassium-sparing diuretic (11). Such characteristics of this diuretic may explain the induction of natriuresis without kaliuresis as observed in the present study.

The present results on the left ventricular and vascular hypertrophy in SHR in comparison with WKY are in good agreement with those documented in the previous papers $(14,23)$. Besides lowering the blood pressure, M17055 in a dose range of 2.5 and $5 \mathrm{mg} / \mathrm{kg} / \mathrm{day}$ significantly reduced the $\mathrm{LV} / \mathrm{BW}$ in a dose-dependent manner. Captopril at a dose of $30 \mathrm{mg} / \mathrm{kg} / \mathrm{day}$ also exerted a significant reduction either on the blood pressure or the $\mathrm{LV} / \mathrm{BW}$. The extent of blood pressure decrease by captopril was almost the same as that induced by M17055 at a dose of $5 \mathrm{mg} / \mathrm{kg} /$ day, whereas the LV/BW was significantly $(\mathrm{P}<0.01)$ lower in the group treated with the dose of $5 \mathrm{mg} / \mathrm{kg} /$ day of M17055. These results suggest that the effect of M17055 on the treatment of cardiac hypertrophy is more potent than that by captopril under a comparable condition of antihypertensive effect.

It is generally recognized that ACE inhibitors reduce the pressure load and sodium load via the suppression of angiotensin II and enhancement of bradykinin. Such an effect of ACE inhibitors may contribute to improve the cardiac hypertrophy (24). However, the direct inhibition of the tissue renin-angiotensin system within the heart is also considered as a possible mechanism for ACE inhibitor action on cardiac hypertrophy $(25-27)$. After the treatment with M17055 at a dose of $5 \mathrm{mg} / \mathrm{kg} /$ day, the plasma renin activity was elevated and the plasma aldosterone concentration tended to elevate, indicating that this diuretic activated the renin-angiotensin system. Therefore, it is difficult to explain the mechanism of action of M17055 on cardiac hypertrophy in the similar manner to that for ACE inhibitors. Harmsen and Leenen (28) have suggested that high sodium intake is inclined to increase left ventricular weight without any change in blood pressure both in human essential hypertension and hypertensive rats. Accordingly, one possible mechanism would be due to the removal of excessive sodium in the body via the natriuretic effect of M17055 as a diuretic. Another possibility might be a direct action within the heart. Although there is no direct evidence that a loop diuretic would possess any beneficial biochemical effect in connection with cardiac cells, the possible involvement of the $\mathrm{Na}{ }^{+}, \mathrm{K}^{+}, 2 \mathrm{Cl}^{-}$-cotransport system during the development of hypertension and vascular hypertrophy has been suggested $(29,30)$. Therefore, it is assumed that the $\mathrm{Na}^{+}$, $\mathrm{K}^{+}, 2 \mathrm{Cl}^{-}$-cotransport system, which may be inhibitable with M17055 as well as the other loop diuretics, would be involved in the development of cardiovascular hypertrophy. Furthermore, based on the fact that M17055 has an amiloride-like action in the distal nephron segments, another ion transport system, such as $\mathrm{Na}^{+} / \mathrm{H}^{+}$exchanger, could be speculated as a target of M17055 in its preventive action on cardiac hypertrophy.

Concerning vascular hypertrophy, we measured the media/lumen ratio $(M / L)$ in the thoracic aorta and mesenteric arteries. In the aorta, M17055 did not significantly reduce the $\mathrm{M} / \mathrm{L}$ at any doses, whereas captopril did. In the mesenteric arteries, however, M17055 at a dose of 5 $\mathrm{mg} / \mathrm{kg} /$ day significantly reduced the $\mathrm{M} / \mathrm{L}$. Lee et al. (14) have reported that the vascular medial enlargement in SHR is due to a couple of different mechanisms, i.e., one is the hypertrophy of the smooth muscle cells and the other is the increase in the number of smooth muscle cells. The way of enlargement depends on the size of the vessels and the age of the animals. Therefore, the difference in the altering effects of M17055 found between the aorta and the mesenteric arteries may be explained by such a difference in the development of vascular hypertrophy. It is well documented that ACE inhibitors including captopril improve the vascular structure in the mesenteric arteries of SHR $(23,31,32)$. It is pointed out that the development of blood pressure after the withdrawal of the long-term treatment of ACE inhibitors in SHR closely relates to the vascular structure of the mesenteric arteries $(31,32)$. In this context, it should be emphasized that M17055 at a dose of $5 \mathrm{mg} / \mathrm{kg} /$ day significantly reduced the $M / L$ of the mesenteric arteries. Such an effect of M17055 may offer a reasonable explanation for the longlasting antihypertensive effect after the withdrawal of this agent as previously demonstrated (33). As for the mechanism of developing and sustaining the vascular hypertrophy, the tissue renin-angiotensin system has been indicated to be involved $(23,26)$. On the other hand, the involvement of the $\mathrm{Na}^{+}, \mathrm{K}^{+}, 2 \mathrm{Cl}^{-}$-cotransport system $(29,30)$ or $\mathrm{Na}^{+} / \mathrm{H}^{+}$exchanger (34) should be considered, being similar to the case with cardiac hypertrophy. However, the mechanism for the vascular action of M17055 remains to be elucidated. Further investigations are required to clarify the precise mechanism through which M17055 improves cardiovascular hypertrophy.

To estimate the adverse effect of M17055 in the treatment of hypertension, we assessed the plasma electrolytes, lipid profiles and the renal function parameters on the day after the last dosage. M17055 did not induce any changes in plasma concentrations of electrolytes, triglyceride, total cholesterol, urea nitrogen and creatinine. These results suggest that the adverse effect of M17055 on electrolyte and lipid metabolism and renal function is negligible during the 24-day treatment. This property of M17055, together with the profitable effect on cardiovascular hypertrophy and diuretic action without increment of urinary $\mathrm{K}^{+}$excretion, contributes not only to the 
prevention of ischemic heart disease but also to the longterm efficacy of antihypertensive therapy. These results observed in the present study suggest that M17055 may be beneficial for the clinical treatment of hypertension.

\section{Acknowledgments}

We would like to express our thanks to Dr. Kazutoshi Yanagibashi for his helpful discussions and thank Ms. Takane Sato for her technical assistance.

\section{REFERENCES}

11988 Joint National Committee: The 1988 Report of the Joint National Committee on Detection, Evaluation, and Treatment of High Blood Pressure. Arch. Intern. Med. 148, 1023-1038 (1988)

2 Lithell, H.O.L.: Effect of antihypertensive drugs on insulin, glucose, and lipid metabolism. Diabetes Care 14, 203-209 (1991)

3 Grimm, R.H., Leon, A.S., Hunninghake, D.B., Lenz, K., Hannan, P. and Blackburn, H.: Effects of thiazide diuretics on plasma lipids and lipoproteins in mildly hypertensive patients. Ann. Intern. Med. 94, 7-11 (1981)

4 Kannel, W.B.: Risk factors in hypertension. J. Cardiovasc. Pharmacol. 13, Supp. I, 4-10 (1989)

5 Cruickshank, J.M., Fox, K. and Collins, P.: Meta-analysis of hypertension treatment trials (letter). Lancet 335, 1092 (1990)

6 Schmieder, R.E. and Messerli, F.H.: Reversal of left ventricular hypertrophy: A desirable therapeutic goal? J. Cardiovasc. Pharmacol. 16, Supp. 6, S16-S22 (1990)

7 Messerli, F.H. and Soria, F.: Does a reduction in left ventricular hypertrophy reduce cardiovascular morbidity and mortality? Drugs 44, Supp. 1, 141-146 (1992)

8 Strauer, B.E., Bayer, F., Brecht, H.M. and Motz, W.: The influence of sympathetic nervous activity on regression of cardiac hypertrophy. J. Hypertens. Supp. 3, S39-S44 (1985)

9 Schmider, R.E.: Risk reduction following regression of cardiac hypertrophy. Clin. Exp. Hypertens. A12, 903-916 (1990)

10 Shinkawa, T., Nakajima, H., Nishijima, K., Yamasaki, F., Kato, K., Ohzawa, N. and Mizota, M.: A novel quinolinone diuretic M12285 and its activation mechanism through sulfate conjugation. Eur. J. Pharmacol. 219, 217-224 (1992)

11 Shinkawa, T., Yamasaki, F., Notsu, T., Nakakuki, M., Nishijima, K., Yoshitomi, K. and Imai M.: Loop and distal actions of a novel diuretic, M17055. Eur. J. Pharmacol. 238, 317-325 (1993)

12 Shinkawa, T., Yamasaki, F., Kikuchi, A., Nakakuki, M., Nishijima, K., Uemura, A., Mizota, M. and Orita, Y.: Pharmacological properties of the novel highly potent diuretic 7-chloro2,3-dihydro-1-(2-methylbenzoyl)-4( $1 H$ )-quinolinone 4-oxime$O$-sulfonic acid potassium salt. Arzneimittelforschung 42, 1466- 1472 (1992)

13 Richer, C., Mulder, P., Richard, V., Caemiller, J.P. and Giudicelli, J.F.: Hemodynamic and morphological effects of quinapril during genetic hypertension development. J. Cardiovasc. Pharmacol. 18, 631-642 (1991)

14 Lee, R.M.K.W., Garfield, R.E., Forrest, J.B. and Daniel, E.E.: Morphometric study of structural changes in the mesenteric blood vessels of spontaneously hypertensive rats. Blood Vessels 20, 57-71 (1983)
15 Novo, S., Abrignani, M.G., Corda, M. and Strano, A.: Cardiovascular structural changes in hypertension: Possible regression during long-term antihypertensive treatment. Eur. Heart J. 12, Supp. G, 47-53 (1991)

16 Giles, T.D.: Antihypertensive therapy and cardiovascular risk. Are all antihypertensives equal? Hypertension 19, Supp. I, I-124-I-129 (1992)

17 Sen, S., Tarazi, R.C. and Bumpus, F.M.: Cardiac hypertrophy and antihypertensive therapy. Cardiovasc. Res. 11, 427-433 (1977)

18 Frohlich, E.: Is reversal of left ventricular hypertrophy in hypertension beneficial? Hypertension 18, Supp. I, 133-138 (1991)

19 Pecker, M.S.: Pathophysiologic effects and strategies for longterm diuretic treatment of hypertension. In HypertensionPathophysiology, Diagnosis, and Management, Edited by Laragh, J.H. and Brenner, B.M., Vol. 2, pp. 2143-2167, Raven Press, New York (1990)

20 Multiple Risk Factor Intervention Trial Research Group: Multiple risk factor intervention trial: risk factor changes and mortality results. JAMA 248, $1465-1477$ (1982)

21 Multiple Risk Factor Intervention Trial Research Group: Baseline rest electrocardiographic abnormalities, antihypertensive treatment, and mortality in the multiple risk factor intervention trial. Am. J. Cardiol. 55, 1-15 (1985)

22 Kannel, W.B., Cupples, L.A., D'Agostino, R.B. and Stokes, J., III: Hypertension, antihypertensive treatment, and sudden coronary death: the Framingham study. Hypertension 11, Supp. II, II-45-II-50 (1988)

23 Lee, R.M.K.W., Berecek, K.H., Tsoporis, J., McKenzie, R. and Triggle, R.: Prevention of hypertension and vascular changes by captopril treatment. Hypertension 17, 141-150 (1991)

24 Harrap, S.B., Mitchell, G.A., Casley, D.J., Mirakian, C. and Doyle, A.E.: Angiotensin II, sodium, and cardiovascular hypertrophy in spontaneously hypertensive rats. Hypertension 21, $50-55$ (1993)

25 Dzau, V.J.: Molecular and physiological aspects of tissue reninangiotensin system: emphasis on cardiovascular control. J. Hypertens. 6, Supp. 3, S7-S12 (1988)

26 Nagano, M., Higaki, J., Mikami, H., Nakamura, M., Higashimori, K., Katahira, K., Tabuchi, Y., Moriguchi, A., Nakamura, F. and Ogihara, T.: Converting enzyme inhibitors regressed cardiac hypertrophy and reduced tissue angiotensin II in spontaneously hypertensive rats. J. Hypertens. 9, 595-599 (1991)

27 Paul, M. and Ganten, D.: The molecular basis of cardiovascular hypertrophy: The role of the renin-angiotensin system. J. Cardiovasc. Pharmacol. 19, Supp. 5, S51-S58 (1992)

28 Harmsen, E. and Leenen, H.H.: Dietary sodium induced cardiac hypertrophy. Can. J. Physiol. Pharmacol. 70, 580-586 (1992)

29 Orlov, S.N., Resink, J., Bernhardt, J. and Bühler, F.R.: $\mathrm{Na}^{+}-\mathrm{K}^{+}$ pump and $\mathrm{Na}^{+}-\mathrm{K}^{+}$co-transport in cultured vascular smooth muscle cells from spontaneously hypertensive and normotensive rats: baseline activity and regulation. J. Hypertens. 10, $733-740$ (1992)

30 Tseng, $\mathrm{H}$. and Berk, B.C.: The $\mathrm{Na} / \mathrm{K} / 2 \mathrm{Cl}$ cotransporter is increased in hypertrophied vascular smooth muscle cells. J. Biol. Chem. 267, $8161-8167$ (1992)

31 Christensen, K.L., Jespersen, L.T. and Mulvany, M.J.: De- 
velopment of blood pressure in spontaneously hypertensive rats after withdrawal of long-term treatment related to vascular structure. J. Hypertens. 7, 83-90 (1989)

32 Freslon, J.L. and Giudicelli, J.F.: Compared myocardial and vascular effects of captopril and dihydralazine during hypertension development in spontaneously hypertensive rats. Br. J. Pharmacol. 80, 533-543 (1983)

33 Uemura, A., Shinkawa, T., Kikuchi, A., Kitamoto, A., Takase, A., Yamaguchi, K., Inaba, H., Kosuzume, H., Suzuki,
Y., Aizawa, N., Mochida, E. and Orita, Y.: Antihypertensive effect of 7-chloro-1-(2-methyl)benzoyl-2,3-dihydro-4( $I H)$ quinolinone-4-oxime-o-sulfate potassium salt (M17055), a novel potent diuretic. Abstract of 12th Scientific Meeting of the International Society of Hypertension, Kyoto, 0717 (1988)

34 Bobik, A., Grooms, A., Little, P.J., Cragoe, E.J., Jr. and Grinpukel, S.: Ethylisopropylamiloride-sensitive pH control mechanisms modulate vascular smooth muscle cell growth. Am. J. Physiol. 260, C581-C588 (1991) 